\title{
Lung mechanics in subjects showing increased residual volume without bronchial obstruction
}

\author{
S VULTERINI, M R BIANCO, L PELLICCIOTTI, AND A M SIDOTI \\ From the Divisione di Medicina Generale, Ospedale Fatebenefratelli, Rome, Italy
}

ABSTRACT Fourteen subjects showing an increase of residual volume (RV) without any clinical or functional signs of bronchial obstruction were studied. Maximum expiratory flow volume (MEFV) curves were obtained with a pressure-corrected volume plethysmograph. Static pressurevolume curves were obtained by stepwise interruption of a slow expiration from total lung capacity (TLC) to RV. Static compliance was measured by the slope of pressure-volume curve between functional residual capacity (FRC) and FRC $+20 \%$ of TLC. Maximum flow static recoil (MFSR) curves were constructed by plotting MEF obtained from MEFV curves against elastic pressure (Pst) obtained from pressure-volume curves at the same lung volumes. Most patients demonstrated a decrease of MEF $50 \%$ and $25 \%$ of VC. From the MFSR curves it was clear that this reduction was not the result of increased airways resistance, but rather of loss of elastic recoil. Most patients showed a significant decrease of Pst at different volumes and changes seem likely to be evidence of emphysema.

Residual volume is determined by the point at which the pressure produced by the muscles of expiration is dissipated entirely on the elastic recoil of the respiratory system. Increase in residual volume may result from loss of elastic recoil, any form of airways obstruction, or both. The purpose of this work was to study some aspects of lung mechanics in subjects with an increased residual volume in the absence of any evidence of bronchial obstruction.

\section{Methods}

We examined 14 patients, 13 men and one woman, with a mean age of $45.5 \pm 8.92$ years (range 29$56 \mathrm{yr}$ ). These subjects complained of minor respiratory disability, mainly slight exertional dyspnoea. All save one were smokers-three smoked less than 10 cigarettes per day, the remainder 15-20.

Clinical examination showed no signs of cardiac disease or bronchial obstruction and all chest radiographs were considered to be normal. Study of respiratory function showed only an increase, in comparison with normal values, ${ }^{1}$ of residual volume measured by plethysmography, the average increase being $58 \cdot 14 \% \pm 26 \cdot 33$ (range: $+32-104 \%$ ).

Address for reprint requests: Dr S Vulterini, Divisione di Medicina Generale, Ospedale Fatebenefratelli, Isola Tiberina, Rome, Italy.
Vital capacity (VC), forced expiratory volume in one second $\left(\mathrm{FEV}_{1}\right)$, forced expiratory volume in one second/vital capacity ratio $\times 100\left(\mathrm{FEV}_{1} /\right.$ VC), and airways resistance (Raw) were close to predicted values in every patient (table 1 ).

Vital capacity and FEV ${ }_{1}$ were measured with a pneumotachograph (Jaeger) coupled to a pressure transducer (Jaeger) and were obtained by integration of the flow measured at the mouth and recorded on an X-Y recorder. The result was taken as the best of two or three efforts and the volumes, at BTPS, were expressed as a percentage of the predicted normal values for sex, height, and age. ${ }^{2}$ Functional residual capacity was determined by a constant volume body plethysmograph (Pneumotest-Bodytest Jaeger, Würzburg) which also allowed, with a single manoeuvre, the simultaneous measurement of VC. Although the spirometric and plethysmographic values of VC were almost identical we calculated RV from plethysmography. Functional residual capacity was measured in duplicate. An approximation of $250 \mathrm{ml}$ or less was required for two successive determinations. From the FRC, TLC, RV, and RV/TLC were calculated.

We adopted the normal values of Amrein et al ${ }^{1}$ for RV, FRC, TLC, and RV/TLC ratio. These values are not significantly different from those 
Table 1 Lung function values of 14 subjects showing only increased residual volume without any signs of bronchial obstruction

\begin{tabular}{|c|c|c|c|c|c|c|c|c|c|}
\hline Number & $\operatorname{Sex}$ & $\begin{array}{l}\text { Age } \\
(y r)\end{array}$ & $V C^{*}$ & $F E V_{1} *$ & $F E V_{1} / V C^{*}$ & $\boldsymbol{R} \boldsymbol{V} \dagger$ & $T L C+$ & $R V / T L C \dagger$ & $\begin{array}{l}\text { Raw } \\
\left(\mathrm{kPal}^{-1} s\right)\end{array}$ \\
\hline & $\mathbf{M}$ & 49 & 80 & 78 & 98 & 225 & 103 & 200 & $0 \cdot 17$ \\
\hline 21 & $\mathbf{M}$ & 35 & 93 & 113 & 118 & 136 & 91 & 140 & $0 \cdot 14$ \\
\hline 3 & $\mathbf{M}$ & 36 & 115 & 120 & 104 & 145 & 101 & 141 & $0 \cdot 14$ \\
\hline 4 & $\mathbf{M}$ & 43 & 77 & 75 & 96 & 146 & 82 & 165 & $0 \cdot 13$ \\
\hline 5 & $\mathbf{M}$ & 52 & 105 & 118 & 111 & 154 & 102 & 143 & $0 \cdot 16$ \\
\hline 6 & $\mathbf{M}$ & 51 & 99 & 96 & 97 & 161 & 102 & 151 & 0.20 \\
\hline 7 & $\mathbf{M}$ & 52 & 88 & 79 & 89 & 177 & 96 & 166 & 0.19 \\
\hline 8 & $\mathbf{F}$ & 40 & 80 & 74 & 91 & 224 & 115 & 200 & $0 \cdot 12$ \\
\hline 9 & $\mathbf{M}$ & 38 & 104 & 108 & 102 & 140 & 96 & 136 & 0.14 \\
\hline 10 & $\mathbf{M}$ & 48 & 82 & 77 & 84 & 194 & 98 & 176 & $0 \cdot 16$ \\
\hline 11 & $\vec{M}$ & 56 & 108 & 100 & 93 & 193 & 119 & 164 & 0.21 \\
\hline 12 & $\mathbf{M}$ & 54 & 91 & 88 & 96 & 210 & 110 & 185 & 0.20 \\
\hline 13 & $\mathbf{M}$ & 29 & 102 & 100 & 97 & 137 & 97 & 133 & 0.17 \\
\hline 14 & $\mathbf{M}$ & 56 & 115 & 110 & 95 & 151 & 110 & 138 & $0 \cdot 11$ \\
\hline
\end{tabular}

*Expressed as a percentage of the predicted normal value proposed by Cotes 2 .

$\dagger$ Expressed as a percentage of the predicted normal value proposed by Amrein et al. ${ }^{1}$

of Cotes, ${ }^{2}$ except for RV/TLC which is significantly lower $(\mathrm{p}<0.05)$. In our 14 cases the predicted mean values of $R V / T L C$ was $27 \pm 3 \cdot 10$ according to Amrein $e t$ al and $31 \pm 2 \cdot 8$ by Cotes. The functional residual capacity and RV of every patient were expressed as a percentage of the respective predicted values.

Airways resistance (Raw) was obtained during tidal breathing by the slope of the line traced between inspiratory and expiratory flows of $0.51 \mathrm{~s}^{-1}$. Five measures were made in sequence and we calculated the average of the last three. The predicted values of Raw are those of Amrein et al. ${ }^{1}$

Maximum expiratory flow volume (MEFV) curves were obtained with the patient sitting in the pressure-corrected, volume plethysmograph (Pneumotest-Bodytest Jaeger, Würzburg). To relate maximum flow rates to lung static recoil we chose the plethysmographic volume measurements, since static recoil pressure depends on the actual lung volumes, regardless of alveolar gas compression. ${ }^{3}$ An appropriate device prevents the response time of the flow channel exceeding that of the volume recording channel. Volume change measured in the plethysmograph was recorded on the abscissa, and flow, measured at the mouth, on the ordinate. The curves were registered on a $\mathrm{X}-\mathrm{Y}$ recorder. The best of three or four attempts was chosen for the measurement of MEF. The curve was quantified by measuring MEF at lung inflation of $75 \%, 50 \%$, and $25 \%$ of VC. As normal reference values we adopted those of Cherniack et al. ${ }^{4}$

Intraoesophageal pressure was measured using the method of Milic-Emili et al. ${ }^{5}$ An oesophageal balloon (length $9 \mathrm{~cm}$, wall thickness about $0.04 \mathrm{~mm}$ ) was placed in the middle third of the oesophagus and tested for freedom from artefacts. With the patient sitting in the plethysmograph, $\vec{c}$ three or four static pressure-volume curves wereog obtained by stepwise interruption of a slow expir-ation from TLC to RV. Transpulmonary pressureo (Pst), expressed as the difference between mouth and oesophageal pressure, was measured with a differential pressure transducer (Jaeger). The curves were registered on an X-Y recorder, pro- ducing volume change on the ordinate and Pst on $\overrightarrow{\vec{O}}$ the abscissa. The "best" of them was used to measure Pst at different volumes. The "best curve" covers a range of volume, from TLC to RV, as: close as possible to $\mathrm{VC}$ of the patient and is free from potential errors in elastic recoil estimation which are mainly caused by active oesophaegal ${ }^{\times}$ contractions, arising while or shortly before re- 3 cording the curve.

Values of Pst at different volumes and of static $\stackrel{3}{3}$ compliance (Cstat) were found to be reproducible. Static pressure-volume curves were obtained by the above-mentioned method on five different dayso in eight normal subjects, aged from 20-24 years. When the above criteria were not satisfied, theor curves were discarded and the study was repeated $N$ on the following days. A total of 240 validN measurements was, therefore, obtained in these $\omega$ subjects, the six values Cstat, Pst $100 \%, 90 \%$ $80 \%, 70 \%$, and $60 \%$ of TLC for each of the five days. Mean values of the five measures of Cstat $\stackrel{\oplus}{-}$ and Pst at different volumes are given in table 2 . In every subject all values for the same measure- $\overline{0}$ ment fell within the range of \pm 2 SD.

Predicted values for Pst were derived from the $\frac{\Omega}{\Phi}$ data of Yernault et al. ${ }^{6}$ Static compliance was $\stackrel{\varrho}{\sigma}$ measured by the slope of the pressure-volume curve between FRC and FRC $+20 \%$ of TLC. 
Table 2 Mean values (x), standard deviation (SD), and coefficient of variation $(C V)$ of five measures of static compliance (Cstat) and transpulmonary pressure (Pst) at different volumes percent of TLC, obtained on five different days in eight normal subjects

\begin{tabular}{|c|c|c|c|c|c|c|c|c|c|c|c|c|c|c|c|c|c|}
\hline \multirow[t]{2}{*}{ Subjects. } & \multicolumn{2}{|c|}{$\begin{array}{l}\text { Pst } 100 \% \mathrm{TLC} \\
(\mathrm{kPa}) \\
\end{array}$} & \multicolumn{3}{|c|}{$\begin{array}{l}\text { Pst } 90 \% T L C \\
(\mathrm{kPa}) \\
\end{array}$} & \multicolumn{3}{|c|}{$\begin{array}{l}\text { Pst } 80 \% T L C \\
\underline{(k P a)} \\
\end{array}$} & \multicolumn{3}{|c|}{$\begin{array}{l}\text { Pst } 70 \% T L C \\
(\mathrm{kPa})\end{array}$} & \multicolumn{3}{|c|}{$\begin{array}{l}\text { Pst } 60 \% \mathrm{TLC} \\
(\mathrm{kPa})\end{array}$} & \multicolumn{3}{|c|}{$\begin{array}{l}\text { Cstat } \\
\left.\qquad \mathrm{kPa}^{-1}\right) \\
\end{array}$} \\
\hline & $\overline{\bar{x}} \quad S D$ & $\mathrm{CV}(\%)$ & $\overline{\bar{x}}$ & $S D$ & $C V(\%)$ & $\overline{\bar{x}}$ & $S D$ & $C V(\%)$ & $\overline{\bar{x}}$ & $S D$ & $C V(\%)$ & $\overline{\bar{x}}$ & $S D$ & $C V(\%)$ & $\overline{\bar{x}}$ & $S D$ & $C V(\%)$ \\
\hline $\begin{array}{l}1 \\
2 \\
3 \\
4 \\
5 \\
5 \\
6 \\
7 \\
8\end{array}$ & $\begin{array}{l}4.62 \pm 0.38 \\
4.65 \pm 0.17 \\
2 \cdot 84 \pm 0.36 \\
2.83 \pm 0.19 \\
2 \cdot 49 \pm 0.47 \\
2.03 \pm 0 \cdot 22 \\
3.06 \pm 0.34 \\
2.76 \pm 0.45\end{array}$ & $\begin{array}{c}8 \cdot 2 \\
4 \\
13 \\
7 \\
19 \\
11 \\
11 \\
17\end{array}$ & $\begin{array}{l}2.3 \\
1.9 \\
1.4 \\
1.5 \\
1.2 \\
1.0 \\
2.0 \\
1.5\end{array}$ & $\begin{array}{l} \pm 0.26 \\
\pm 0.10 \\
\pm 0.13 \\
\pm 0.06 \\
\pm 0.27 \\
\pm 0.14 \\
\pm 0.21 \\
\pm 0.11\end{array}$ & $\begin{array}{rr}6 & 11 \\
0 & 5 \\
3 & 9 \\
6 & 4 \\
7 & 21 \\
4 & 13 \\
1 & 10 \\
1 & 7\end{array}$ & $\begin{array}{l}1.94 \\
1.60 \\
1.22 \\
1.28 \\
0.87 \\
0.89 \\
1.75 \\
1.28\end{array}$ & $\begin{array}{l} \pm 0.16 \\
\pm 0.07 \\
\pm 0.11 \\
\pm 0.09 \\
\pm 0.13 \\
\pm 0.06 \\
\pm 0.14 \\
\pm 0.07\end{array}$ & $\begin{array}{l}8 \cdot 2 \\
4 \\
9 \\
7 \\
15 \\
7 \\
8 \\
6\end{array}$ & & $\begin{array}{l}5 \pm 0.08 \\
\pm 0.06 \\
\pm 0.08 \\
\pm 0.09 \\
5 \pm 0.13 \\
9 \pm 0.06 \\
3 \pm 0.10 \\
0 \pm 0.12\end{array}$ & $\begin{array}{r}5 \cdot 1 \\
4 \\
7 \\
9 \\
20 \\
9 \\
7 \\
12\end{array}$ & $\begin{array}{l}1 \cdot 3 \\
0.9 \\
0 \cdot 8 \\
0 \cdot 7 \\
0 \cdot 3 \\
0 \cdot 4 \\
1 \cdot 2 \\
0.7\end{array}$ & $\begin{array}{l} \pm 0.11 \\
\pm 0.02 \\
\pm 0.09 \\
\pm 0.11 \\
\pm 0.06 \\
\pm 0.09 \\
\pm 0.08 \\
\pm 0.04\end{array}$ & $\begin{array}{l}8 \cdot 3 \\
2 \\
11 \\
14 \\
1 \cdot 5 \\
19 \\
6 \\
5\end{array}$ & & $\begin{array}{l}0 \pm 0.90 \\
2 \pm 0.04 \\
7 \pm 0.08 \\
0 \pm 0.09 \\
4 \pm 0.23 \\
9 \pm 0.05 \\
8 \pm 0.08 \\
4 \pm 0.04\end{array}$ & $\begin{array}{c}4 \cdot 7 \\
2 \\
3 \\
3 \\
10 \\
2 \\
7 \\
1\end{array}$ \\
\hline
\end{tabular}

Predicted values of Cstat, as a function of height, are those proposed by Yernault and Englert. ${ }^{7}$

Maximum flow static recoil (MFSR) curves $^{8}$ were constructed by plotting MEF obtained from MEFV curves against corresponding Pst calculated from static pulmonary pressure-volume curves at the same lung volumes.

Table 3 Maximum expiratory flow at $75 \%, 50 \%$, and $25 \%$ of vital capacity. Mean values and standard deviation in 14 subjects showing only increased residual volume in the absence of signs of bronchial obstruction

\begin{tabular}{|c|c|c|c|c|c|c|}
\hline \multirow[t]{2}{*}{ Subjects } & \multicolumn{2}{|c|}{$\begin{array}{l}M E F 75 \% V C \\
\left(l s^{-1}\right)\end{array}$} & \multicolumn{2}{|c|}{$\begin{array}{l}M E F 50 \% V C \\
\left(l s^{-1}\right)\end{array}$} & \multicolumn{2}{|c|}{$\begin{array}{l}M E F 25 \% V C \\
\left(l s^{-1}\right)\end{array}$} \\
\hline & \multicolumn{2}{|c|}{ ObservedPredicted* } & \multicolumn{4}{|c|}{ ObservedPredicted ${ }^{*}$ ObservedPredicted ${ }^{*}$} \\
\hline $\begin{array}{r}1 \\
2 \\
3 \\
4 \\
5 \\
6 \\
7 \\
8 \\
9 \\
10 \\
11 \\
12 \\
13 \\
14\end{array}$ & $\begin{array}{r}7.5 \\
9.5 \\
10.5 \\
9.6 \\
8.0 \\
6.0 \\
6.0 \\
6.5 \\
8.5 \\
6.7 \\
7.5 \\
6.0 \\
8.2 \\
10.5\end{array}$ & $\begin{array}{l}8 \cdot 4 \\
9 \cdot 5 \\
9 \cdot 2 \\
9 \cdot 2 \\
8.9 \\
8 \cdot 9 \\
8 \cdot 4 \\
5 \cdot 8 \\
9 \cdot 2 \\
8 \cdot 8 \\
9 \cdot 4 \\
9 \cdot 2 \\
9.5 \\
8 \cdot 6\end{array}$ & $\begin{array}{l}5 \cdot 0 \\
4 \cdot 5 \\
4 \cdot 7 \\
4 \cdot 0 \\
2 \cdot 7 \\
3 \cdot 5 \\
4 \cdot 0 \\
3 \cdot 7 \\
4 \cdot 7 \\
3 \cdot 0 \\
3 \cdot 0 \\
3.0 \\
4 \cdot 0 \\
4 \cdot 0\end{array}$ & $\begin{array}{l}5 \cdot 2 \\
5 \cdot 8 \\
5 \cdot 8 \\
5 \cdot 5 \\
5 \cdot 3 \\
5 \cdot 3 \\
4 \cdot 9 \\
4 \cdot 5 \\
5 \cdot 7 \\
5 \cdot 2 \\
5 \cdot 2 \\
5 \cdot 3 \\
5 \cdot 9 \\
5 \cdot 1\end{array}$ & $\begin{array}{l}1.2 \\
1.5 \\
1.7 \\
1.5 \\
0.7 \\
1.5 \\
1.0 \\
1.5 \\
2.0 \\
1.0 \\
0.7 \\
1.2 \\
2.0 \\
1.5\end{array}$ & $\begin{array}{l}2 \cdot 3 \\
2 \cdot 6 \\
2 \cdot 9 \\
2 \cdot 7 \\
2 \cdot 2 \\
2 \cdot 3 \\
2 \cdot 2 \\
2 \cdot 4 \\
2 \cdot 8 \\
2 \cdot 3 \\
2 \cdot 3 \\
2 \cdot 2 \\
3 \cdot 2 \\
2 \cdot 0\end{array}$ \\
\hline $\begin{array}{l}\text { Mean } \\
\text { value }\end{array}$ & 7.9 & $8 \cdot 8$ & 3.9 & $5 \cdot 3$ & $1 \cdot 3$ & $2 \cdot 5$ \\
\hline SD & 1.6 & 0.9 & 0.7 & 0.4 & 0.5 & $0 \cdot 3$ \\
\hline p & NS & & $<0.001$ & & $<0.00$ & \\
\hline
\end{tabular}

*Predicted values according to Cherniack et al.4

\section{Results}

The MEF values of 14 patients who showed an increase of residual volume, calculated from the flow volume loop at $75 \%, 50 \%$, and $25 \%$ of $\mathrm{VC}$, are given in table 3. Most patients had decreased MEF values at different volumes. In comparison with the predicted values, the average decrease of MEF $50 \%$ and MEF $25 \%$ was highly significant $(p<0.001)$. On the other hand the decrease of MEF $75 \%$ was not significant.

It should be emphasised that, unlike MEF, for which predicted values are usually given as a percentage of VC, normal reference data of Pst, as a rule, are indicated as a percentage of TLC, and we have followed this convention in the statistical evaluation of our results.

Static compliance and Pst values at $100 \%, 90 \%$, $80 \%, 70 \%$, and $60 \%$ of TLC are given in table 4 . Ten of 14 subjects showed an increase of Cstat, but there was no significant difference between the mean value of Cstat obtained in these individuals and the mean predicted value. Most patients however showed a decrease of Pst at different volumes of TLC. As a rule, the mean value of Pst measured at a given volume was significantly decreased in comparison with the mean predicted normal value, with the exception of Pst $100 \%$ of TLC.

The figure shows the maximum flow-static recoil (MFSR) curves of the 14 patients examined. Since the curves are constructed by plotting MEF against Pst at the same lung volumes, both of them are in this case expressed as a percentage of VC. Because MEF varies with lung size, flow in $1 \mathrm{sec}^{-1}$ at different volumes was divided in each patient, according to Mead et al, ${ }^{8}$ by individual TLC and plotted on the ordinate. Transpulmonary pressure, expressed as a percentage of VC (table 5), is plotted on the abscissa.

The figure also presents three MFSR curves, derived from Mead et al, ${ }^{8}$ each being the mean curve of five normal subjects in the age groups 24-30, 38-43, and 48-61 yr, and, as an example, 
Table 4 Static compliance (Cstat) and transpulmonary pressure (Pst) at $100 \%, 90 \%, 80 \%, 70 \%, 60 \%$ of $T L C^{*}$ and mean values $\pm S D$ in 14 subjects showing only increased residual volume

\begin{tabular}{|c|c|c|c|c|c|c|c|c|c|c|c|c|}
\hline \multirow[t]{2}{*}{ Subjects } & \multicolumn{2}{|c|}{$\begin{array}{c}\text { Cstat } \\
\left(I k P^{1}\right)\end{array}$} & \multicolumn{2}{|c|}{$\begin{array}{l}\text { Pst } \\
100 \% T L C \\
(k P a)\end{array}$} & \multicolumn{2}{|c|}{$\begin{array}{l}\text { Pst } \\
90 \% T L C \\
(k P a)\end{array}$} & \multicolumn{2}{|c|}{$\begin{array}{l}P s t \\
80 \% T L C \\
(k P a)\end{array}$} & \multicolumn{2}{|c|}{$\begin{array}{l}\text { Pst } \\
70 \% T L C \\
(k P a)\end{array}$} & \multicolumn{2}{|c|}{$\begin{array}{l}P s t \\
60 \% T L C \\
(k P a)\end{array}$} \\
\hline & \multicolumn{2}{|c|}{ ObservedPredicted $\dagger$} & \multicolumn{2}{|c|}{ ObservedPredicted $\dagger$} & \multicolumn{2}{|c|}{ ObservedPredicted $\dagger$} & \multicolumn{2}{|c|}{ ObservedPredicted $\dagger$} & \multicolumn{2}{|c|}{ ObservedPredicted $\dagger$} & \multicolumn{2}{|c|}{ ObservedPredicted $\dagger$} \\
\hline 1 & $2 \cdot 2$ & $2 \cdot 4$ & $2 \cdot 4$ & $2 \cdot 4$ & $1 \cdot 2$ & $2 \cdot 4$ & 0.9 & $1 \cdot 0$ & 0.6 & 0.8 & $0 \cdot 3$ & 0.5 \\
\hline 2 & $4 \cdot 7$ & $3 \cdot 0$ & $2 \cdot 5$ & $2 \cdot 9$ & 0.7 & $1 \cdot 6$ & 0.6 & $1 \cdot 2$ & 0.4 & 0.9 & 0.3 & 0.7 \\
\hline 3 & $2 \cdot 6$ & $2 \cdot 7$ & $3 \cdot 4$ & $3 \cdot 0$ & $1 \cdot 2$ & $1 \cdot 6$ & $1 \cdot 0$ & $1 \cdot 3$ & 0.7 & 0.9 & 0.5 & 0.7 \\
\hline 4 & $4 \cdot 1$ & $2 \cdot 9$ & $2 \cdot 3$ & $2 \cdot 6$ & 0.7 & $1 \cdot 5$ & 0.5 & $1 \cdot 1$ & 0.4 & 0.8 & 0.3 & 0.6 \\
\hline 5 & $5 \cdot 1$ & $2 \cdot 9$ & $1 \cdot 5$ & $2 \cdot 3$ & 0.9 & $1 \cdot 3$ & 0.7 & $1 \cdot 0$ & 0.6 & 0.7 & 0.5 & 0.5 \\
\hline 6 & $2 \cdot 9$ & $2 \cdot 9$ & $2 \cdot 4$ & $2 \cdot 3$ & $1 \cdot 1$ & $1 \cdot 3$ & 0.9 & $1 \cdot 0$ & 0.7 & 0.7 & 0.6 & 0.5 \\
\hline 7 & $4 \cdot 1$ & $2 \cdot 2$ & $1 \cdot 6$ & $2 \cdot 3$ & 0.8 & $1 \cdot 3$ & 0.7 & 1.0 & 0.5 & 0.7 & 03 & 05 \\
\hline 8 & $1 \cdot 7$ & 1.9 & $2 \cdot 1$ & $2 \cdot 4$ & $1 \cdot 4$ & 1.4 & $1 \cdot 0$ & 1.0 & 0.7 & 0.8 & 0.4 & 0.5 \\
\hline 9 & $6 \cdot 1$ & 2.9 & $1 \cdot 1$ & $2 \cdot 8$ & 0.6 & $1 \cdot 6$ & 0.5 & $1 \cdot 2$ & 0.4 & 0.9 & 0.3 & 0.6 \\
\hline 10 & $3 \cdot 5$ & $2 \cdot 5$ & 1.9 & $2 \cdot 5$ & 0.9 & 1.4 & 0.7 & $1 \cdot 0$ & 0.5 & 0.8 & 0.3 & 0.5 \\
\hline 11 & $5 \cdot 3$ & $3 \cdot 6$ & $1 \cdot 6$ & $2 \cdot 2$ & 0.7 & $1 \cdot 2$ & 0.5 & 0.9 & 0.3 & 0.7 & 0.1 & 0.5 \\
\hline 12 & $3 \cdot 6$ & $3 \cdot 1$ & $1 \cdot 0$ & $2 \cdot 2$ & $1 \cdot 0$ & $1 \cdot 3$ & 0.7 & 0.9 & 0.5 & 0.7 & 0.3 & 0.5 \\
\hline 13 & $3 \cdot 3$ & $2 \cdot 7$ & $2 \cdot 7$ & $3 \cdot 1$ & $1 \cdot 3$ & $1 \cdot 7$ & $1 \cdot 1$ & $1 \cdot 3$ & 0.9 & $1 \cdot 0$ & 0.7 & 0.7 \\
\hline 14 & $3 \cdot 5$ & $2 \cdot 7$ & $2 \cdot 4$ & $2 \cdot 2$ & $1 \cdot 0$ & $1 \cdot 2$ & 0.8 & 0.9 & 0.6 & 0.7 & 0.5 & 0.5 \\
\hline Mean & $3 \cdot 8$ & $2 \cdot 7$ & $2 \cdot 1$ & $2 \cdot 5$ & 0.9 & $1 \cdot 4$ & $0 \cdot 8$ & $1 \cdot 1$ & 0.6 & 0.8 & 0.4 & 0.6 \\
\hline \multirow[t]{2}{*}{ SD } & $1 \cdot 2$ & 0.4 & 0.7 & $0 \cdot 3$ & $0 \cdot 2$ & $0 \cdot 2$ & $0 \cdot 2$ & $0 \cdot 1$ & $0 \cdot 2$ & $0 \cdot 1$ & $0 \cdot 1$ & $0 \cdot 1$ \\
\hline & \multicolumn{2}{|l|}{ NS } & \multicolumn{2}{|l|}{ NS } & \multicolumn{2}{|c|}{$<0.005$} & \multicolumn{2}{|c|}{$<0.01$} & \multicolumn{2}{|c|}{$<0.02$} & \multicolumn{2}{|c|}{$<0.05$} \\
\hline
\end{tabular}

* Pst values at different volumes are given as a percentage of TLC, since their predicted values are most commonly indicated in this way. †Predicted values according to Yernault et al. ${ }^{6}$

an MFSR curve obtained in a patient with severe bronchial obstruction. Although most patients showed decreased values of MEF, the figure demonstrates that the slopes of the MFSR curves were normal or even shifted to the left in some cases. Thus the decrease of MEF in these subjects showing only an increase of RV is the result of a reduction of elastic recoil rather than of airways obstruction. Indeed, if the flow reduction were caused by an increase of airways resistance, the MFSR curve should be shifted to the right of the normal curve.

Table 5 Transpulmonary pressure (Pst) at $75 \%$, $60 \%, 50 \%, 40 \%$, and $25 \%$ of vital capacity obtained in 14 subjects showing only increased residual volume

\begin{tabular}{llllll} 
Subjects & \multicolumn{1}{l}{ Pst } & \multicolumn{1}{l}{} \\
\cline { 2 - 6 } & $75 \%$ & $60 \%$ & $50 \%$ & $40 \%$ & $25 \%$ \\
& $(k P a)$ & $(k P a)$ & $(k P a)$ & $(k P a)$ & $(k P a)$ \\
\hline 1 & 1.2 & 1.0 & 0.7 & 0.5 & 0.35 \\
2 & 0.65 & 0.5 & 0.4 & 0.32 & 0.2 \\
3 & 1.1 & 0.85 & 0.7 & 0.55 & 0.32 \\
4 & 0.7 & 0.45 & 0.4 & 0.32 & 0.2 \\
5 & 0.75 & 0.6 & 0.5 & 0.37 & 0.25 \\
6 & 0.95 & 0.75 & 0.65 & 0.56 & 0.55 \\
7 & 0.8 & 0.6 & 0.47 & 0.37 & 0.25 \\
8 & 1.35 & 1.1 & 0.9 & 0.75 & 0.6 \\
9 & 0.55 & 0.45 & 0.37 & 0.3 & 0.17 \\
10 & 0.85 & 0.7 & 0.55 & 0.45 & 0.35 \\
11 & 0.77 & 0.55 & 0.45 & 0.35 & 0.27 \\
12 & 0.95 & 0.75 & 0.6 & 0.5 & 0.3 \\
13 & 1.1 & 0.85 & 0.65 & 0.56 & 0.35 \\
14 & 0.9 & 0.7 & 0.6 & 0.47 & 0.28 \\
\hline
\end{tabular}

\section{Discussion}

Reduction in expiratory forced flows can be at $\frac{2}{0}$ tributed to two main factors, reduction in recoil pressure or an increase in airways resistance. By⿳⺈ relating maximal expiratory flow to lung recoib we obtain MFSR curves, as described by Meadô et al. ${ }^{8}$ By means of this curve it is possible to understand the mechanisms of expiratory flowo limitation. If the MFSR curve, plotted from these data, were shifted to the right towards the abscissao (see dashed line of figure), it would show that, at any given Pst, MEF would be less than normal.o Hence, in this instance, loss of retractive force is not sufficient in itself to explain the low MEF, 음 but increased airways resistance must be respon- $\rightarrow$ sible. On the other hand, should the decrease of MEF be caused by reduction of elastic recoil, then slope of the MFSR curve would be close to normat or even shifted to the left. It is apparent in thiso case that although MEF is decreased, it is essenti- $-\omega$ ally normal for the available Pst values. In other words, because of the reduction of MEF, the MFSR curve is shorter than normal, but its sloped is nearly normal in the absence of bronchial ob-struction. Thus, the decreased MEF could be ex- $-\frac{T}{0}$ plained by the decreased Pst.

Both loss of recoil and any form of airways ob- $\frac{\mathrm{O}}{\circ}$ struction predisposing to airways closure may re- $\triangle$ sult in an increase in RV. Under these circum stances RV is determined by the amount of airo 


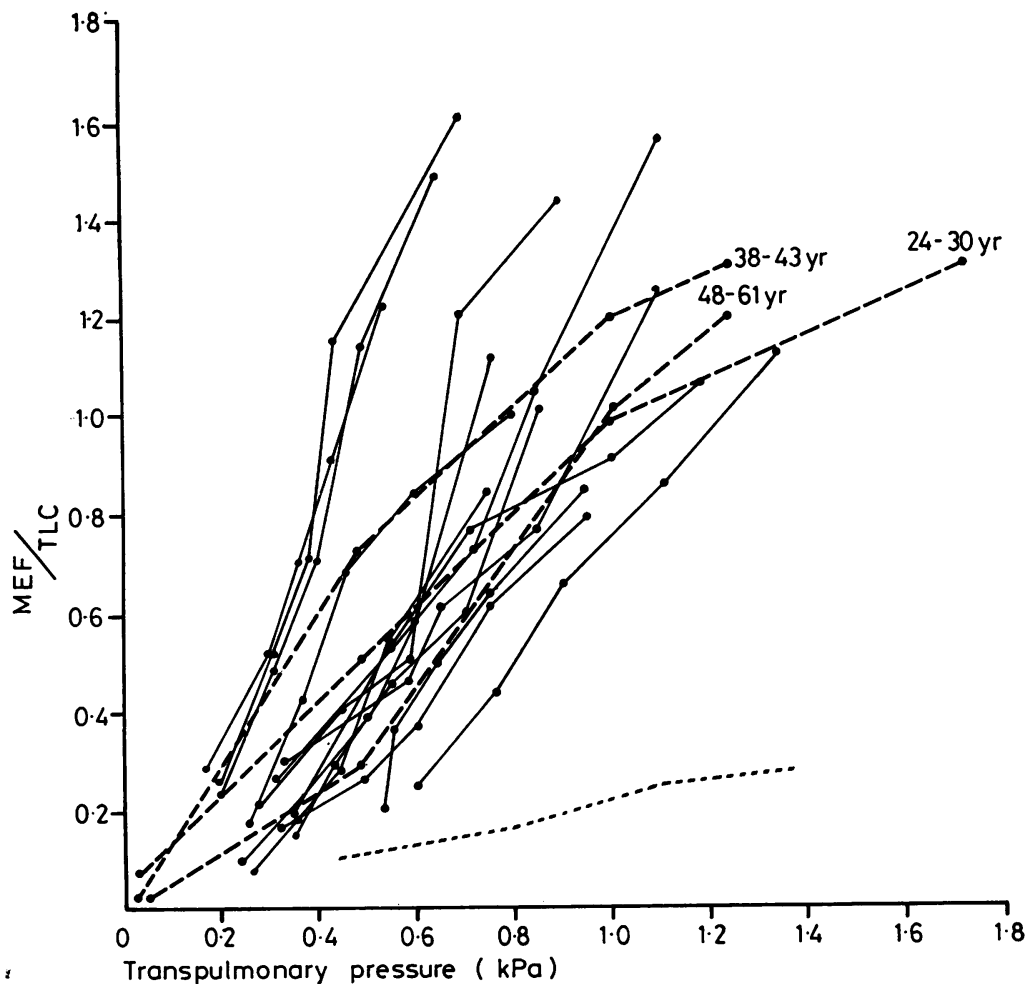

Figure Maximum flow static recoil (MFSR) curves (.-.-.) of 14 subjects showing increased residual volume without bronchial obstruction. Each of the three thick broken lines (---) represents the mean MFSR curve of five normal subjects, age groups as indicated (derived from Mead et al ${ }^{8}$ ). The thin dashed line (-.-) shows the MFSR curve of a patient with severe bronchial obstruction. trapped in the lungs when the airways are almost all closed. The increase in airways closure at low lung volumes in the elderly is caused mainly by loss of elastic recoil, resulting in airways closure at a higher lung volume than in the young. ${ }^{9}$

Most of the subjects we studied demonstrated a decrease of MEF $50 \%$ and $25 \%$ of VC. By means of the MFSR curve it was apparent that this reduction was not the result of increased airways resistance, but rather of loss of elastic recoil. In support of this Pst at $90 \%, 80 \%, 70 \%$, and $60 \%$ of TLC of the 14 patients showed a significant decrease in comparison to predicted values.

Our results thus demonstrate that in most subjects showing only an increase in residual volume, loss of elastic recoil is the main mechanism. We noticed that while MEF $50 \%$ and $25 \%$ of VC were significantly less than normal, MEF $75 \%$ was not. A possible explanation for this could be that the increase in the cross-sectional diameter of airways at high volumes compensates for the loss of elastic recoil. The effect of these opposing influences is such that MEF at high lung volumes shows little change. At lower volumes, where frictional resistance increases as a function of reduc- tion of the cross-sections of airways, the decrease of MEF, from loss of elastic recoil, becomes more and more evident.

Gelb et $a l^{10}$ studied some patients with a localised lung lesion one week before thoracotomy. Decrease of Pst, a low single breath lung diffusing capacity, and reduced MEF at low lung volumes were found in seven patients. Vital capacity, TLC, $\mathrm{FEV}_{1}$, and Raw, however, were normal or very close to normal. Anatomical studies of lobes or lungs removed within a week of these physiological studies revealed diffuse emphysema in all seven patients.

A displacement to the left of the static pressurevolume curve was observed by Hoeppner et al ${ }^{11}$ in a group of asymptomatic smokers compared with a control group of non-smokers. On the other hand static compliance was similar in both smokers and non-smokers. This means that measurement of Pst at different lung volumes should be preferred, at least in the diagnosis of incipient emphysema, to the evaluation of static compliance. Of course in the advanced stages of emphysema the pressure-volume curve is displaced to the left, but there is also an 
increase in the slope-that is, an increase of static compliance. ${ }^{12}$

On the basis of the above data it seems to us that subjects such as ours, with no airways obstruction but with raised $R V$, probably have emphysema, causing reduction of MEF at medium and low lung volumes as well as the decrease of Pst at different volumes, although static compliance appears to be close to normal.

\section{References}

1 Amrein R, Keller R, Joos H, Herzog H. Valeurs theoriques nouvelles de l'exploration de la function ventilatoire du poumon. Bull Physiopathol Respir 1970; 6:317-49.

2 Cotes JE. Lung function assessment and application in medicine. Third edition. Oxford: Blackwell, 1975.

3 Ingram RH, Schilder DP. Effect of gas compression on pulmonary pressure, flow and volume relationship. J Appl Physiol 1966; 22:1821-6.

4 Cherniack RM, Raber MB. Normal standards for ventilatory function using an automated wedge spirometer. Am Rev Respir Dis 1972; 106: $38-46$.
5 Milic-Emili J, Mead J, Turner JM, Glauser EM $\vec{C}$ Improved technique for estimating pleural press:ure from esophageal balloons. J Appl Physio 1964; 19:207-11.

6 Yernault JC, Englert M, Baran D. Effect of growth and aging on static mechanical lung pro® perties. Bull Physiopathol Respir 1977; 13:777-880

7 Yernault JC, Englert M. Static mechanical lung properties in young adults. Bull PhysiopathaP Respir 1974; 10:435-50.

8 Mead J, Turner JM, Macklem PT, Little JBळ Significance of the relationship between lung ref coil and maximum expiratory flow. J A ppl Physio* 1967; 22:95-108.

9 Holland J, Milic-Emili J, Macklem PT et aị Regional distribution of pulmonary ventilatio and perfusion in elderly subjects. $J$ Clin Invest 1968; 47:81-92.

10 Gelb AF, Gold WM, Wright HR et al. Physiologiediagnosis of subclinical emphysema. Am ReE Respir Dis 1973; 107:81-6.

11 Hoeppner VH, Cooper DM, Zamel N et al. Relationship between elastic recoil and closing volume in smokers and non-smokers. Am ReP Respir Dis 1974; 109:81-6.

12 Stanescu DC. Early detection of chronic bron chitis and pulmonary emphysema. Leiden: Sten fert Kroese, 1976. 